\title{
Atualização no tratamento do tabagismo (Parte 3)
}

\section{Autoria: Antônio Pedro Mirra, Wanderley Marques Bernardo}

1. 0 tratamento farmacológico do tabagismo deve ser diferente em gestantes?
a) O uso de bupropiona, vareniclina, nortriptilina e clonidina em gestantes não está contraindicado;
b) 0 uso de bupropiona, vareniclina, nortriptilina e clonidina em gestantes tem contraindicações relativas;
c) A terapia de reposição de nicotina pode levar a parto prematuro;
d) A terapia de reposição de nicotina não produz efeitos adversos na gestante.

2. Qual a abordagem para a cessação do tabagismo deve ser recomendada para os adolescentes?
a) Folhetos informativos;
b) Aconselhamento;
c) Terapia de reposição de nicotina;
d) Bupropiona.

3. 0 tratamento do tabagismo de pacientes com transtornos psiquiátricos deve ser diferente do realizado em outros fumantes?
a) 0 tratamento deve ser diferente ao oferecido à população geral;
b) A concomitância com distúrbios psiquiátricos não aumenta o risco de recaída;
c) Especial atenção durante o tratamento com vareniclina o qual pode estar associado a humor depressivo, agitação e ideação ou comportamento suicida;
d) A abordagem aumenta a sobriedade relativa à condição de base em longo prazo.

\section{Programas de cessação do tabagismo intra-hospitalares são efetivos?}

a) O uso de terapia de reposição de nicotina e bupropiona não são seguros nos pacientes hospitalizados;

b) O seguimento após a alta não é importante;

c) Documentar a situação do paciente: fumante, nunca fumante, ex-fumante, está entre os itens para intervenção hospitalar;

d) O modelo de intervenção não deve associar aconselhamento e medicação.

\section{A eficácia do tratamento do tabagismo é diferente entre homens e mulheres?}
a) O receio do ganho ponderal pode ser obstáculo para a cessação em homens;
b) A presença de depressão é obstáculo para a cessação em mulheres;
c) As mulheres não se beneficiam das mesmas intervenções para os homens ;
d) A terapia de reposição de nicotina pode ser mais efetiva em mulheres.

\section{Respostas ao Cenário Clínico: Tabagismo (Parte 2) [Publicado na RAMB 2010; 56(3)]}

1. A combinação pode melhorar o controle dos sintomas de abstinência (Alternativa $\mathbf{B}$ ).

2. Bupropiona e doença cerebrovascular (Alternativa D).

3. Adesivos de nicotina de $21 \mathrm{mg}$, passando por $14 \mathrm{mg}$ e depois $7 \mathrm{mg}$ por 6 semanas (Alternativa A)

4. Em usuários de outras formas de tabaco (Alternativa $\mathbf{C}$ ).

5. Fumantes com sintomas de abstinência persistentes podem se beneficiar (Alternativa $\mathbf{A}$ ). 